\title{
Time to read the fine print
}

\author{
Ashish S. Shah, MD \\ From the Department of Cardiac Surgery, Vanderbilt University Medical Center, Nashville, Tenn. \\ Disclosures: Author has nothing to disclose with regard to commercial support. \\ Received for publication Aug 5, 2017; accepted for publication Aug 28, 2017; available ahead of print Sept 19, \\ 2017. \\ Address for reprints: Ashish S. Shah, MD, Vanderbilt Medical Center East, 1215 21st Ave South, Suite 5025, \\ Nashville, TN 37232 (E-mail: ashish.s.shah@vanderbilt.edu). \\ J Thorac Cardiovasc Surg 2018;155:189 \\ $0022-5223 / \$ 36.00$ \\ Copyright (C) 2017 by The American Association for Thoracic Surgery \\ http://dx.doi.org/10.1016/j.jtcvs.2017.08.077
}

Over the past 10 years, US health care policy directed by thinkers in Boston, Annapolis, and Washington, DC, have advanced an important and ambitious agenda. Although most hospitals, health systems, and cardiac surgery practices have focused on volume, the new policy people have moved on to value, cost-effectiveness, and cost containment. This is formally operationalized in programs initially by rewarding quality. Over time, Medicare then moves to penalizing programs for poor performance-both clinical and financial.

The current study by Hawkins and colleagues ${ }^{1}$ in the Virginia Quality Consortium has used a large set of statewide data to model coronary artery bypass grafting reimbursement in this new world in which doing more cases does not solve everything. It is an important study that merits reading and re-reading. The analysis suggests that the current proposed Medicare payment scheme would ultimately lead to significant payment variability and large penalties to programs depending on patient risk and the increasing cost of isolated coronary artery bypass grafting.

The study essentially looks at the fine print and frankly is a warning. As demonstrated in their retrospective review and others, 1,2 there is significant variation in coronary artery bypass grafting costs within the state, and when Medicare begins limiting payments by considering regional costs, many $(>70 \%)$ hospitals will be penalized by 5 years. When cardiac surgery loses $\$ 2,000,000$ for your hospital, I suspect you will get a phone call.

What Hawkins and colleagues ${ }^{1}$ fail to account for is that over time, we do change behavior, adapt to the rules of the game, and find a new equilibrium between our value to patients and to the health system. In other words, their analysis is predicated on not adjusting to the penalties over time. Most of us have been subjected to bundled payments

\section{References}

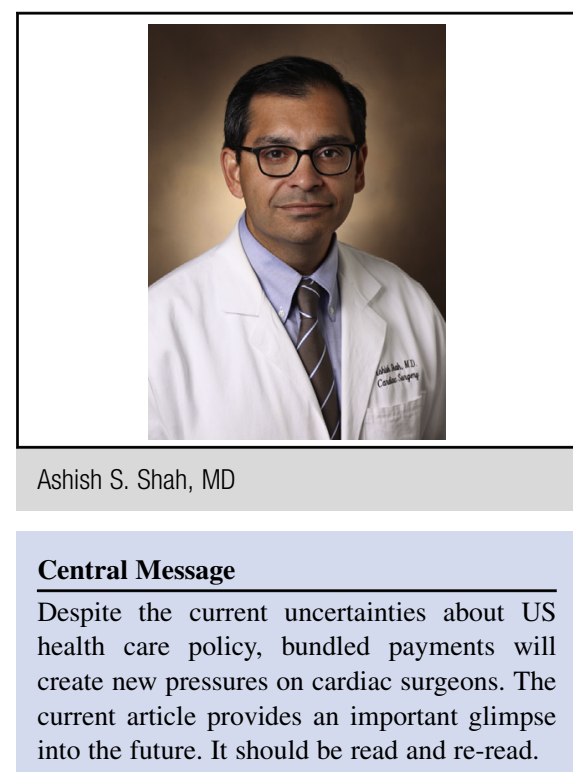

See Article page 182.

methodologies, care pathways, and even case costs reported in real time, and they influence our behavior.

Procedural volume is a fundamental part of quality, but it will not preserve our value to the health system. Quality, innovation, and cost containment will be the foundation of 21 st century health care, all of which will be articulated, like it or not, by the payers and, in particular, government. In this complex scheme, it will be in the fine print. Read it. There are very specific rules and definitions that shape payment and importantly penalties. We all need to understand them and in many ways master this vocabulary and the methodology that will ultimately affect our compensation and professional life.

1. Hawkins RB, Mehaffey JH, Yount KW, Yarboro LT, Fonner C, Kron IL, et al Statewide impact of coronary artery bypass grafting bundled payment proposal. J Thorac Cardiovasc Surg. 2018;155:182-8.

2. Kilic A, Shah AS, Conte JV, Mandal K, Baumgartner WA, Cameron DE, et al. Understanding variability in hospital-specific costs of coronary artery bypass grafting represents an opportunity for standardizing care and improving resource use. $J$ Thorac Cardiovasc Surg. 2014;147:109-15. 